\title{
Pemeliharaan ramah lingkungan Hotel Mandalawangi Tasikmalaya berbasis ASEAN green hotel standard
}

\section{Eco-friendly maintenance of Hotel Mandalawangi Tasikmalaya based on ASEAN green hotel standard}

\author{
N. Fadjarwati ${ }^{1}$, N. R. Nurzakiah ${ }^{1 *}$ \\ 1Program Studi Manajemen Aset, Jurusan Administrasi Niaga, Politeknik Negeri Bandung, Bandung, \\ Indonesia
}

\begin{abstract}
Abstrak.
Perubahan iklim merupakan tantangan bagi operasional bisnis salah satunya yakni bisnis hotel. Untuk mengatasi perubahan iklim tersebut, pelaku bisnis mencari solusi yang dapat memberikan keberlanjutan dengan konsep green hotel. Green hotel memiliki konsep operasional dan pemeliharaan yang ramah lingkungan. Salah satu hotel yang menerapkan konsep green hotel adalah Hotel Mandalawangi yang berlokasi di Kota Tasikmalaya. Tujuan penelitian ini adalah untuk mengetahui pemeliharaan di Hotel Mandalawangi dengan teknik metode pengumpulan data dengan wawancara dan observasi lalu membandingkan dengan kriteria standar green hotel ASEAN. Hasil penelitian menunjukkan bahwa Hotel Mandalawangi telah melaksanakan 59,25\% dari total kriteria persyaratan green hotel ASEAN, sehingga Hotel Mandalawangi perlu mengurangi penggunaan zat kimia, mengoptimalkan operasional dan pemeliharaan yang telah ada dan melaksanakan program pelatihan bagi sumber daya manusia.
\end{abstract}

\begin{abstract}
.
Climate change is a challenge for business operations like hotel business. To deal with climate change, businesses are looking for solutions that can give a sustainability with the green hotel concept. Green hotels have environmentally friendly operations and maintenance. One of the hotels that applies the green hotel concept is the Mandalawangi Hotel located in the Tasikmalaya City. The purposes of this study was to determine the maintenance at the Mandalawangi Hotel with the technique of data collection methods by interview and observation, then comparing with the ASEAN green hotel standard criteria for certification. The results showed that the Mandalawangi Hotel has implemented $59.25 \%$ of the total criteria for ASEAN green hotel requirements. Mandalawangi Hotel requires to reduce the use of chemicals, optimize the existing operations and maintenance also carry out training programs for hotel's human resources.
\end{abstract}

Keywords: maintenance, eco-friendly, green hotel standard

Kata kunci: pemeliharaan, ramah lingkungan, standar green hotel

\section{PENDAHULUAN}

Seiring berjalannya waktu, lingkungan mengalami perubahan. Fenomena perubahan iklim pada awalnya berasal dari pemanasan global yang membuat suhu bumi semakin meningkat. Menurut BMKG (2019), perubahan iklim disebabkan oleh faktor seperti kegiatan manusia dan pemanasan global yang diakibatkan oleh $\mathrm{CO}_{2}$ dan emisi gas lainnya serta adanya kerusakan fungsi hutan. Adanya perubahan iklim merupakan tantangan bagi operasional bisnis. Oleh karena itu, dibutuhkan operasional dan pemeliharaan yang dapat memberikan keberlanjutan bagi bisnis tanpa harus mengganggu keseimbangan dan keberlanjutan lingkungan sekitar.

\footnotetext{
${ }^{*}$ Korespondensi Penulis

Email : nonon.rofi@gmail.com
} 
Salah satu bisnis dalam sektor pariwisata yang diminati oleh masyarakat adalah bisnis hotel. Widanaputra (2009) mendefinisikan hotel adalah suatu jenis akomodasi komersial untuk menyediakan fasilitas pelayanan jasa seperti penginapan, makanan dan minuman serta jasa lainnya yang disediakan untuk para tamu dan masyarakat umum yang ingin menginap. Green hotel merupakan salah satu green product. Oleh karena operasional green hotel dan hotel pada umumnya memiliki perbedaan, maka aktivitas untuk memelihara green hotel dengan hotel biasa memiliki perbedaan pula. Pelaksanaan green hotel masih sangat jarang diimplementasikan. Sebagai bentuk komitmen terhadap tujuan pembangunan berkelanjutan (SDGs), Kementerian Pariwisata melaksanakan apresiasi pada hotel yang menerapkan prinsip berwawasan lingkungan atau green hotel award yang dilaksanakan rutin setiap dua tahun sekali.

Widanaputra (2009) mendefinisikan hotel adalah suatu jenis akomodasi komersial untuk menyediakan fasilitas pelayanan jasa seperti penginapan, makanan dan minuman, serta jasa lainnya yang disediakan untuk para tamu dan masyarakat umum yang ingin menginap. Hotel memiliki banyak jenis seperti hotel kapsul dan green hotel yang merupakan salah satu jenis dari green product. Produk hijau didefinisikan ketika produk tersebut memberikan manfaat yang lebih besar kepada lingkungan dan biaya lingkungan yang lebih kecil. Sustain Ever (2000), mengklasifikasikan green product menjadi beberapa jenis, yaitu green restaurant, green bank, green IT, green university, green hotel, green office, green hospitals dan green building. Menurut Sustain Ever (2000), green hotel adalah hotel yang menekankan pada nilai-nilai lingkungan dan pelestarian lahan di kegiatan sehari-hari serta berfokus pada pemberian layanan berkualitas tinggi dengan mengoptimalkan energi, air dan sumber daya lain serta mengurangi produksi limbah dan polutan. Salah satu kunci dalam keberlangsungan dan keberlanjutan hotel tersebut dengan cara pelaksanaan pemeliharaan hotel.

Pemeliharaan menurut Chan et al. (2001) merupakan suatu usaha antara hubungan teknis dan administrasi untuk menjaga aset fisik atau mengembalikannya ke kondisi yang dapat difungsikan. Ghazi (2016) mendefinisikan pemeliharaan sebagai kunci untuk menyediakan lingkungan bangunan yang lebih baik bagi pengguna bangunan. Pemeliharaan adalah usaha mempertahankan kondisi bangunan agar tetap berfungsi sesuai tupoksi dan sebagai usaha meningkatkan wujud bangunan, serta menjaga dari kemungkinan kerusakan yang dapat terjadi (Kristiana et al. 2017). Berdasarkan pengertian tersebut dapat disimpulkan bahwa pemeliharaan adalah usaha menjaga aset fisik, mengembalikan ke kondisi yang difungsikan dan membuat lingkungan bangunan lebih baik sehingga terhindar dari kerusakan. Pemeliharaan dalam ruang lingkup hotel menurut Ghazi (2016) memiliki beberapa tujuan yaitu untuk meningkatkan keamanan tamu dan pegawai hotel dengan cara memastikan 
bangunan, pelayanan dan fasilitas yang aman dan pas digunakan, meningkatkan stabilitas dan efisiensi operasional fasilitas dan sistem, serta untuk menyesuaikan terhadap kecenderungan baru dan teknologi seperti gerakan penghijauan. Oleh karena itu, pemeliharaan hotel diharapkan dapat memenuhi tujuan pemeliharaan, agar hotel dapat beroperasi secara optimal. Namun kenyataannya, pemeliharaan masih belum dilakukan secara efektif dan efisien.

Beberapa permasalahan dalam pemeliharaan hotel diantaranya personel yang melakukan pemeliharaan terlalu berfokus pada tanggung jawab teknis, kinerja pemeliharaan sulit diukur, kurangnya tujuan pemeliharaan bangunan, sedikitnya penelitian terhadap hotel dan kurangnya catatan terhadap kegiatan pemeliharaan hotel (Ghazi 2016). Faktor-faktor tersebut menjadi alasan mengapa pemeliharaan hotel belum dilakukan secara efektif dan efisien.

Menurut Chan et al. (2003), pemeliharaan hotel diklasifikasikan menjadi empat kategori utama yaitu rutin, korektif, preventif dan emergensi. Pemeliharaan rutin dilakukan dalam periode waktu yang teratur, misalnya harian, bulanan atau sesuai jadwal pemeliharaan. Pemeliharaan korektif dilakukan saat adanya kerusakan pada aset. Pemeliharaan preventif dilakukan sebelum terjadinya kerusakan, sedangkan pemeliharaan emergensi atau darurat dilaksanakan segera setelah terjadinya kerusakan dengan tujuan menghindari kerusakan yang lebih besar. Green hotel dalam pemeliharaannya diwajibkan memakai bahan yang ramah lingkungan dan dapat berkontribusi terhadap peningkatan kualitas lingkungan dan efisiensi energi (Pitt 2016). Dalam operasional dan pemeliharaannya, green hotel memerlukan sertifikasi dan terdapat penghargaan untuk hotel di Indonesia yang sukses melaksanakan green hotel (Rahmafitria 2014). Sejak tahun 2009, sudah dilaksanakan penghargaan bagi 10 green hotel terbaik di Indonesia dan 5 terbaik diajukan ke tingkat ASEAN.

Pada guidelines sertifikasi green hotel standard ASEAN, terdapat beberapa kriteria dan indikator keberhasilan yang ditetapkan meliputi kebijakan lingkungan dan aksi operasional hotel, penggunaan green product, kolaborasi dengan komunitas dan organisasi lokal, pengembangan sumber daya manusia, manajemen limbah padat, efisiensi energi, efisiensi dan kualitas air, manajemen kualitas udara (indoor dan outdoor), kontrol polusi suara, pengelolaan dan perawatan air limbah, racun dan pengelolaan pembuangan substansi kimia. Kebijakan lingkungan dan aksi operasional hotel membutuhkan promosi gerakan ramah lingkungan agar klien dan supplier bersama dengan staf hotel sebagai pemeran utama dapat turut berpartisipasi dalam pengelolaan lingkungan. Pelatihan bagi staf juga dibutuhkan agar dapat meningkatkan kesadaran staf tentang pentingnya lingkungan. Pengoperasian hotel juga memerlukan perencanaan pengelolaan lingkungan dan program monitoring. 
Dalam kriteria penggunaan produk hijau, diperlukan dukungan penggunaan produk lokal dalam operasi hotel seperti makanan yang sehat serta kerajinan. Produk yang digunakan dalam operasional hotel juga harus produk yang ramah lingkungan. Hotel harus melakukan kolaborasi dengan komunitas atau organisasi lokal, aktivitas tersebut akan meningkatkan kualitas hidup dari komunitas serta meningkatkan kesadaran komunitas lokal dalam melindungi lingkungan. Dalam memelihara lingkungan dan hotel, dibutuhkan program pelatihan khusus bagi staf operasi dan pengelolaan lingkungan selama satu atau dua tahun. Pelatihan ini sangat penting bagi semua staf hotel (Ivancevich 2001).

Salah satu kriteria lainnya adalah pengelolaan limbah. Staf hotel perlu dikenalkan dengan teknik mengelola limbah seperti reduce, reuse dan recycle, serta pemisahan sampah dan kompos. Hal tersebut akan meningkatkan aktivitas yang berkaitan dengan pengelolaan sampah dan tamu yang datang diharapkan ikut berpartisipasi seperti membuang sampah pada tempatnya.

Efisiensi energi merupakan salah satu tujuan pemeliharaan. Sebelum dapat melakukan efisiensi energi, staf hotel diharapkan dapat mengikuti pelatihan mengenai teknik menghemat energi, teknologi penghematan energi, atau peralatan hotel yang meminimisasi penggunaan energi. Alat-alat yang dipasang juga harus dapat dipantau sehingga penggunaan energi dapat terkontrol. Tamu hotel juga dapat dilibatkan dalam penghematan energi, seperti mematikan lampu atau AC ketika kamar hotel tidak digunakan (Chen and Peng 2012).

Efisiensi air dan kualitas air adalah kriteria selanjutnya. Dalam praktiknya, hotel perlu menggunakan teknologi yang mengefisienkan konsumsi air. Adanya pemeliharaan rutin untuk peralatan yang menghemat penggunaan air ditunjukkan dengan laporan pemeliharaan dari teknisi serta dukungan atas keterlibatan tamu dalam menghemat air seperti selalu mematikan air jika tidak digunakan atau menggunakan air secukupnya. Staf hotel juga harus memastikan kualitas air di hotel dengan melakukan uji coba kualitas air.

Adanya pengelolaan kualitas udara hotel seperti menyediakan smoking area dan non-smoking area. Hal ini diperlukan agar baik staf atau tamu tidak merokok di sembarang tempat. Adanya monitoring dan pemeliharaan rutin bagi peralatan dan fasilitas hotel juga dapat memastikan kualitas udara. Contohnya adalah ventilasi yang baik atau penggunaan AC yang tidak berlebihan membuat kualitas udara hotel membaik. Kriteria selanjutnya adalah kontrol polusi suara. Hotel harus melaksanakan program yang diimplementasikan di hotel untuk memastikan bahwa ada kontrol suara saat pengoperasian hotel.

Kriteria selanjutnya adalah pengelolaan dan perawatan air limbah. Hal ini dilakukan untuk mencegah air terkontaminasi serta mengurangi adanya air limbah. Hotel juga dapat mempromosikan penggunaan air yang dapat didaur ulang (recycle) dalam pengoperasiannya, contohnya seperti menyiram tanaman 
dan pohon menggunakan air yang telah didaur ulang. Implementasi tersebut perlu didukung sebagai perawatan dan penggunaan air limbah sehingga air dapat digunakan sebagaimana mestinya. Kriteria yang terakhir adalah racun dan pengelolaan pembuangan substansi kimia. Zat kimia merupakan salah satu zat yang berbahaya dan dapat berdampak negatif bagi lingkungan. Harus ada tanda atau rambu-rambu yang tepat bagi penggunaan substansi kimia, baik itu di tempat penyimpanan atau penggunaan bahan kimia di hotel. Pembuangan zat kimia juga harus dilakukan dengan benar agar tidak membahayakan, maka perlu dilakukan pelatihan staf hotel terkait cara-cara untuk menangani bahan kimia.

Salah satu hotel yang menerapkan green hotel adalah Hotel Mandalawangi di Kota Tasikmalaya. Oleh karena itu, diperlukan standardisasi operasi dan pemeliharaan untuk tujuan sertifikasi ASEAN green hotel standard. Penelitian ini diharapkan dapat mengidentifikasi pemeliharaan yang telah dilakukan oleh Hotel Mandalawangi saat ini, menganalisis kesesuaian implementasi pada objek dengan standar green hotel, serta mengevaluasi aspek mana yang perlu dipertahankan, ditingkatkan dan diperbaiki.

\section{METODOLOGI}

\subsection{Lokasi kajian dan waktu penelitian}

Penelitian dilakukan di Hotel Mandalawangi sejak bulan November 2020 hingga Januari 2021. Hotel Mandalawangi didirikan pada tanggal 24 Agustus 1988. Hotel ini berlokasi di Jalan R.E. Martadinata No. 177, Panyingkiran, Kecamatan Indihiang, Kota Tasikmalaya. Hotel ini memiliki konsep pembangunan horizontal dan menerapkan konsep green hotel. Hotel ini dipilih karena sedang berada di tahap pengembangan dan satu-satunya yang menggunakan konsep ramah lingkungan di Kota Tasikmalaya. Gambaran fisik bangunan Hotel Mandalawangi ditampilkan pada Gambar 1.

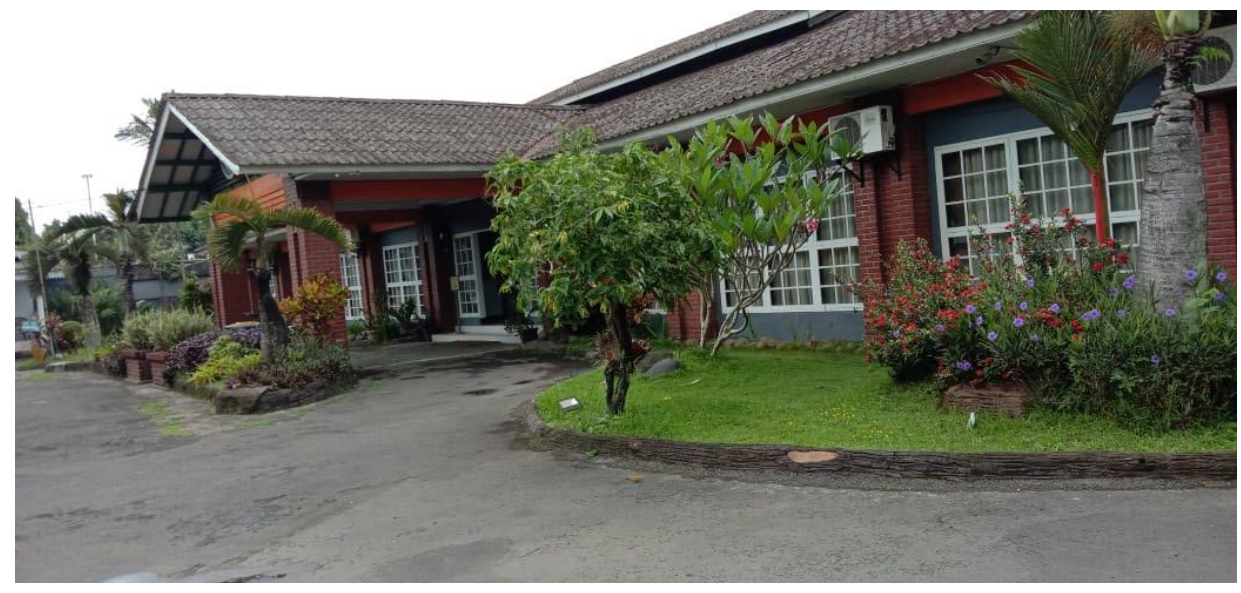

Gambar 1. Hotel Mandalawangi. 
Menurut Yusuf (2014), terdapat empat teknik pengumpulan data, yaitu dengan cara wawancara yaitu kegiatan atau komunikasi secara langsung dengan narasumber, angket merupakan pertanyaan yang ditanyakan kepada responden, observasi merupakan pengumpulan data melalui pancaindra dan pemeriksaan yaitu dilakukan peneliti untuk kegiatan laboratorium. Berdasarkan empat metode tersebut, teknik pengumpulan data yang digunakan dalam penelitian ini yaitu metode wawancara kepada General Manager sekaligus Operating Manager, observasi lapangan, angket yang ditujukan pada staf hotel sebagai data primer dan kajian pustaka dilakukan dengan desk research sebagai data sekunder. Untuk membandingkan kondisi pemeliharaan di Hotel Mandalawangi, peneliti menggunakan standar ASEAN mengenai green hotel.

\subsection{Prosedur analisis data}

Pembobotan dalam penilaian standar ASEAN disusun dalam tabel untuk melihat apakah Hotel Mandalawangi sudah menerapkan kriteria standar green hotel atau belum. Nilai 0 berarti hotel belum melaksanakan persyaratan, sedangkan 1 berarti hotel telah melaksanakan persyaratan. Dalam menghitung pembobotan, dilakukan perhitungan dengan menggunakan Persamaan 1.

Nilai $=\left[\frac{\text { Jumlah bobot }}{\text { total score }}\right] \times 100$

Nilai tersebut disimpulkan untuk menilai apakah hotel telah memenuhi standar berdasarkan ASEAN Green Hotel Standard.

\section{HASIL DAN PEMBAHASAN}

Hotel Mandalawangi telah menerapkan empat jenis pemeliharaan dengan baik dengan membuat perencanaan pemeliharaan yang teratur. Namun, Hotel Mandalawangi belum menerapkan semua konsep ASEAN Green Hotel Standard.

\subsection{Pemeliharaan Hotel Mandalawangi saat ini}

Pemeliharaan di Hotel Mandalawangi terbagi menjadi empat yakni rutin, preventif, korektif dan emergensi. Kegiatan pemeliharaan yang meliputi empat jenis pemeliharaan tersebut secara lengkap dijelaskan dalam Tabel 1.

Tabel 1. Kegiatan pemeliharaan Hotel Mandalawangi.

\begin{tabular}{clcl}
\hline No & Kegiatan & Jenis pemeliharaan & Waktu \\
\hline 1 & Membersihkan peralatan dapur & Rutin & Setiap hari \\
2 & Membersihkan ruangan kamar & Rutin & Sebelum dan sesudah \\
& & & ditempati tamu \\
3 & Menyirami tanaman & Rutin & Setiap hari \\
4 & Membersihkan kolam renang & Rutin & Setiap dua hari sekali \\
\hline
\end{tabular}




\begin{tabular}{clcl}
\hline No & Kegiatan & Jenis pemeliharaan & Waktu \\
\hline 5 & Pengecatan dinding gedung hotel & Rutin & $\begin{array}{l}\text { Setiap enam bulan atau } \\
\text { satu tahun sekali }\end{array}$ \\
& & Rutin & $\begin{array}{l}\text { Setiap dua atau tiga hari } \\
\text { sekali }\end{array}$ \\
6 & $\begin{array}{l}\text { Pengangkutan dan recycle oleh } \\
\text { petugas sampah }\end{array}$ & Preventif & - \\
7 & Penangkal petir & Preventif & Setiap dua hari sekali \\
8 & Menyebarkan kaporit pada & & \\
& kolam renang & Preventif & Saat mati listrik \\
9 & Genset & Preventif & Setiap hari \\
10 & IPAL & Preventif & Setiap hari \\
11 & Area khusus merokok & Korektif & Saat mengalami kerusakan \\
12 & Perbaikan alat fitness yang rusak & Korektif & Saat mengalami kerusakan \\
13 & Pengecoran ulang jalan & Emergensi & Saat mengalami kerusakan \\
14 & Atap yang bocor & & \\
\hline
\end{tabular}

\subsubsection{Rutin}

Pemeliharaan yang dilakukan secara preventif dilakukan secara rutin. Staf food and beverages membersihkan peralatan dapur secara berkala untuk menghindari terjadinya perkaratan atau rusaknya peralatan. Staf housekeeping membersihkan ruangan sebelum dan sesudah tamu menggunakan ruangannya dengan waktu normal 15 menit untuk menghindari terjadinya back-up (tamu belum check out, namun sudah ada tamu yang menunggu untuk check in). Staf garden menyirami tanaman dengan air bersih setiap harinya, memotong dahan agar tidak tumbuh terlalu tinggi, serta membersihkan kolam renang setiap dua hari sekali untuk menghindari lumut dan membuat air tidak kotor terlalu cepat. Dalam pemeliharaan rutin bangunan, dilakukan pengecatan secara periodik yaitu satu kali setiap enam bulan sampai satu tahun.

Hal yang dilakukan hotel selanjutnya adalah menerapkan reduce, reuse dan recycle. Sampah-sampah anorganik disimpan dalam satu tempat di lahan kosong dan menunggu untuk diangkut oleh petugas sampah secara rutin dalam interval dua sampai tiga hari. Oleh karena konsep green hotel bertujuan untuk melakukan pemeliharaan yang efektif dan efisien, hotel ini melakukan efisiensi air dan listrik yang diharapkan dapat menekan biaya pemeliharaan dan operasional bangunan.

\subsubsection{Preventif}

Hotel ini disewa oleh PT Telkom agar dapat dibangun tower jaringan dalam lingkungan hotel. Tower jaringan sangat berpotensi untuk menarik petir, sehingga untuk memelihara dari kejadian tersambar petir, setiap gedung hotel dilengkapi oleh penangkal petir. Tindakan preventif yang lainnya juga adalah memberikan zat kimia seperti kaporit kepada kolam renang agar airnya tidak cepat menguning sebelum pemeliharaan rutin dilakukan. Gambaran kondisi kolam renang yang terdapat di Hotel Mandalawangi dapat dilihat melalui Gambar 2. Selain itu, terdapat genset sebagai langkah pencegahan terhentinya 
operasional jika sewaktu-waktu listrik padam. Di hotel ini terdapat instalasi pengelolaan air limbah (IPAL) dan pengolahan sampah. Hal ini membuktikan bahwa hotel telah melaksanakan pemeliharaan terhadap air bersih dan air limbah. Hotel juga menerapkan kawasan bebas rokok untuk memelihara kesehatan lingkungan.

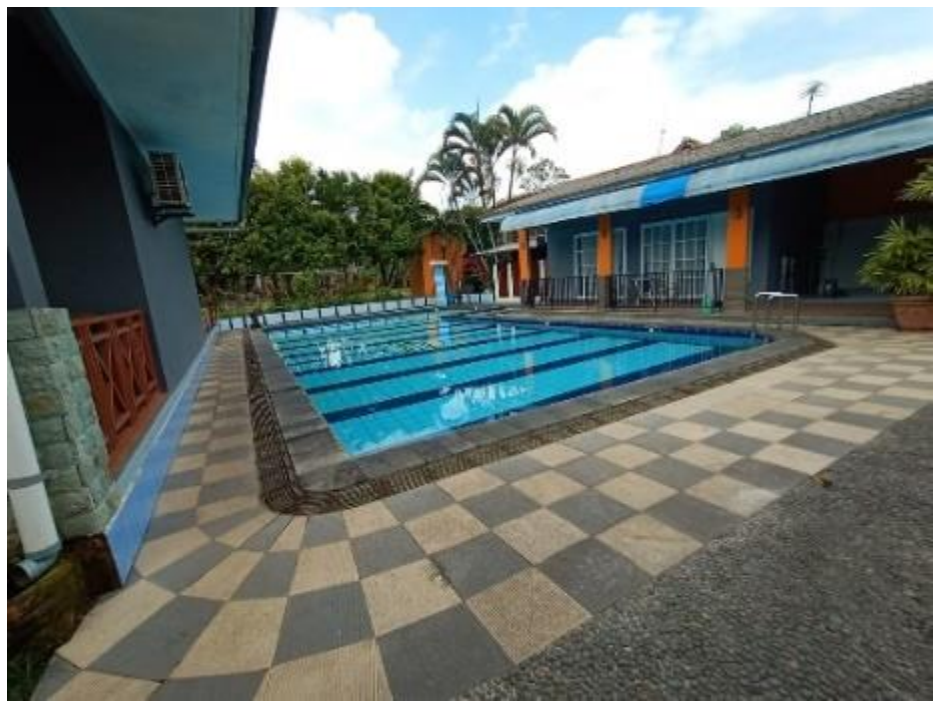

Gambar 2. Kolam renang.

\subsubsection{Korektif}

Pemeliharaan secara korektif dilakukan pada fasilitas yang rusak seperti peralatan olahraga yang rusak, pengecoran ulang, dll. (Gambar 3). Semua kegiatan pemeliharaan dilakukan oleh staf hotel sendiri (bukan outsourcing).

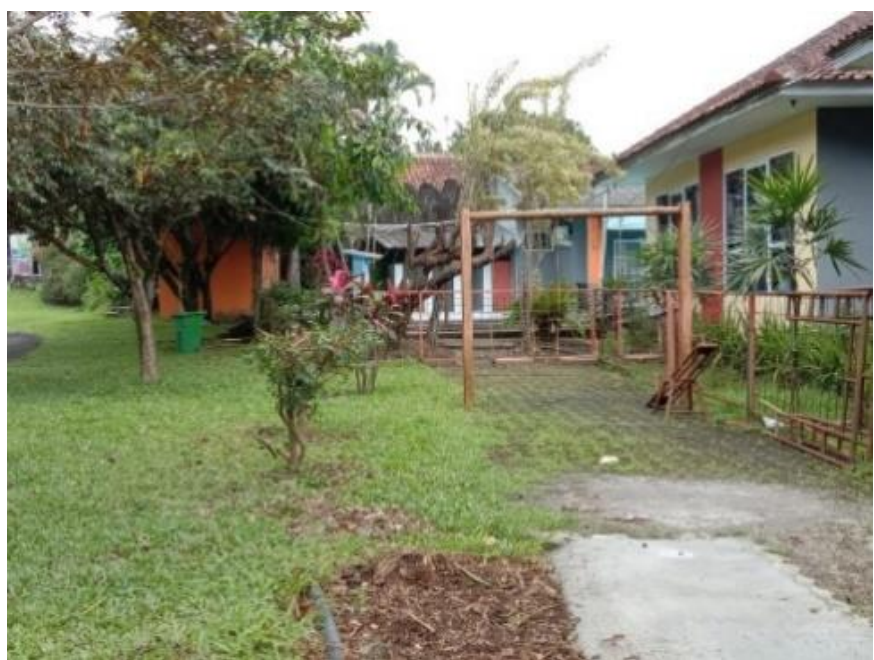

Gambar 3. Perbaikan taman. 


\subsubsection{Emergensi}

Pemeliharaan emergensi yang dilakukan adalah ketika atap hotel mengalami kebocoran, sehingga perlu dilakukan perbaikan yang segera. Pemeliharaan emergensi ini dilakukan oleh staf engineering yang sudah ahli dalam hal teknis dan perbaikan.

\subsection{Penerapan standar green hotel}

Hotel Mandalawangi menerapkan konsep green hotel maka harus dibandingkan pemeliharaan mana saja yang telah dan belum menerapkan konsep green hotel. Untuk memelihara lingkungan yang bebas dari polusi, hotel telah menerapkan kawasan bebas rokok. Hotel juga telah menerapkan reuse, reduce dan recycle sebagai pemeliharaan rutin terhadap sampah yang dihasilkan dari proses operasional. Dalam efisiensi pemeliharaan juga telah menerapkan efisiensi energi listrik, seperti mematikan listrik yang tidak terpakai dan hanya menyalakan listrik saat dibutuhkan serta efisiensi penggunaan air karena air yang digunakan adalah air tanah dan tidak bersumber dari PDAM.

Air limbah yang telah digunakan juga telah dikelola dengan adanya IPAL atau instalasi pengolahan air kotor, sehingga air yang telah digunakan atau air kotor bekas penggunaan tidak akan mencemari lingkungan. Namun, kegiatan seperti memelihara kolam renang masih menggunakan zat kimia, sehingga tidak mengikuti konsep green hotel. Jika dilihat dari kondisi eksisting pemeliharaan yang telah dilakukan oleh Hotel Mandalawangi, maka dasar-dasar operasional green hotel dan pemeliharaannya telah dilakukan dengan baik. Tabel 2 merupakan hasil pembobotan standar green hotel terhadap kondisi yang dimiliki oleh Hotel Mandalawangi.

Tabel 2. Audit persyaratan green hotel standard.

\begin{tabular}{cllc}
\hline No & Kriteria & Persyaratan & Bobot \\
\hline 1 & Kebijakan & Promosi kegiatan lingkungan untuk mendorong \\
& $\begin{array}{l}\text { lingkungan dan aksi } \\
\text { untuk operasi hotel }\end{array}$ & $\begin{array}{l}\text { keterlibatan staf hotel, klien dan pemasok untuk } \\
\text { berpartisipasi di kegiatan pengelolaan ramah } \\
\text { lingkungan } \\
\text { Adanya perencanaan untuk meningkatkan staf agar } \\
\text { lebih sadar terhadap lingkungan } \\
\text { Adanya perencanaan pengelolaan lingkungan untuk } \\
\text { operasi hotel } \\
\text { Adanya program monitoring untuk pengelolaan } \\
\text { lingkungan hotel }\end{array}$ & 0 \\
& & 1 \\
\hline 2 & $\begin{array}{l}\text { Penggunaan produk } \\
\text { hijau }\end{array}$ & $\begin{array}{l}\text { Mendorong penggunaan produk lokal untuk } \\
\text { operasional hotel } \\
\text { Mendorong penggunaan produk yang ramah } \\
\text { lingkungan }\end{array}$ & 0 \\
\hline
\end{tabular}




\begin{tabular}{|c|c|c|c|}
\hline No & Kriteria & Persyaratan & Bobot \\
\hline 3 & $\begin{array}{l}\text { Kolaborasi dengan } \\
\text { komunitas dan } \\
\text { organisasi lokal }\end{array}$ & $\begin{array}{l}\text { Adanya perencanaan atau aktivitas untuk membantu } \\
\text { meningkatkan kualitas hidup dari komunitas } \\
\text { Adanya program meningkatkan kesadaran untuk } \\
\text { komunitas lokal dalam melindungi lingkungan }\end{array}$ & 0 \\
\hline 4 & $\begin{array}{l}\text { Pengembangan } \\
\text { Sumber Daya } \\
\text { Manusia } \\
\end{array}$ & $\begin{array}{l}\text { Menyediakan program pelatihan untuk staf } \\
\text { operasional dan staf manajemen dalam pengelolaan } \\
\text { lingkungan }\end{array}$ & 0 \\
\hline \multirow[t]{3}{*}{5} & $\begin{array}{l}\text { Pengelolaan limbah } \\
\text { padat }\end{array}$ & $\begin{array}{l}\text { Pengenalan teknik pengelolaan limbah seperti } \\
\text { reduce, reuse, recycle, pemisahan sampah dan } \\
\text { pengomposan }\end{array}$ & 0 \\
\hline & & $\begin{array}{l}\text { Mendukung keterlibatan staf hotel dalam reduce, } \\
\text { reuse, recycle, pemisahan sampah dan pengomposan }\end{array}$ & 1 \\
\hline & & $\begin{array}{l}\text { Mendukung keterlibatan tamu hotel dalam reuse, } \\
\text { recycle dan pemisahan sampah }\end{array}$ & 1 \\
\hline \multirow[t]{3}{*}{6} & Efisiensi energi & $\begin{array}{l}\text { Pengenalan teknik menghemat energi dan/atau } \\
\text { teknologi penghemat energi dan peralatan hotel } \\
\text { untuk mengurangi konsumsi energi }\end{array}$ & 1 \\
\hline & & $\begin{array}{l}\text { Instalasi meteran atau peralatan untuk memonitor } \\
\text { konsumsi energi }\end{array}$ & 1 \\
\hline & & $\begin{array}{l}\text { Mendukung keterlibatan tamu hotel dalam } \\
\text { menghemat energi }\end{array}$ & 1 \\
\hline \multirow[t]{4}{*}{7} & $\begin{array}{l}\text { Efisiensi air dan } \\
\text { kualitas air. }\end{array}$ & $\begin{array}{l}\text { Pengenalan teknik menghemat air dan/atau } \\
\text { teknologi penghematan air dan peralatan untuk } \\
\text { mengurangi konsumsi air }\end{array}$ & 1 \\
\hline & & Pemeliharaan rutin untuk peralatan penghemat air & 1 \\
\hline & & $\begin{array}{l}\text { Mendukung keterlibatan tamu hotel dalam } \\
\text { menghemat air }\end{array}$ & 1 \\
\hline & & Memastikan kualitas air yang digunakan di hotel & 1 \\
\hline \multirow[t]{2}{*}{8} & $\begin{array}{l}\text { Manajemen kualitas } \\
\text { udara (dalam dan }\end{array}$ & $\begin{array}{l}\text { Mendesain area khusus merokok dan area dilarang } \\
\text { merokok }\end{array}$ & 1 \\
\hline & luar lingkungan) & $\begin{array}{l}\text { Monitoring dan pemeliharaan rutin untuk peralatan } \\
\text { dan fasilitas hotel untuk memastikan kualitas udara }\end{array}$ & 1 \\
\hline 9 & Kontrol polusi suara & $\begin{array}{l}\text { Adanya program pengontrolan suara dari } \\
\text { operasional hotel }\end{array}$ & 0 \\
\hline \multirow[t]{3}{*}{10} & $\begin{array}{l}\text { Pengontrolan dan } \\
\text { pengelolaan air } \\
\text { limbah (kualitas }\end{array}$ & $\begin{array}{l}\text { Penggunaan mekanisme untuk mencegah } \\
\text { kontaminasi air dan mengurangi timbulnya air } \\
\text { limbah }\end{array}$ & 1 \\
\hline & air) & $\begin{array}{l}\text { Promosi menggunakan air yang dapat di-recycle } \\
\text { dalam operasional seperti menyiram pohon }\end{array}$ & 0 \\
\hline & & $\begin{array}{l}\text { Mendukung kesesuaian penggunaan air limbah yang } \\
\text { telah dikelola }\end{array}$ & 0 \\
\hline \multirow[t]{4}{*}{11} & $\begin{array}{l}\text { Pengelolaan } \\
\text { pembuangan racun }\end{array}$ & $\begin{array}{l}\text { Menyediakan rambu yang jelas untuk substansi } \\
\text { racun }\end{array}$ & 1 \\
\hline & dan substansi kimia & Pengelolaan sampah berbahaya yang sesuai & 1 \\
\hline & & Jumlah persyaratan yang terpenuhi & 16 \\
\hline & & $\begin{array}{r}\text { Total persyaratan } \\
\text { Nilai }\end{array}$ & $\begin{array}{c}27 \\
59,25 \%\end{array}$ \\
\hline
\end{tabular}


Dari 27 persyaratan, terdapat 16 persyaratan yang telah dilaksanakan oleh Hotel Mandalawangi. Hotel Mandalawangi telah melaksanakan sebesar 59,25\% kriteria standar ASEAN green hotel, artinya hotel telah menerapkan setidaknya setengah dari persyaratan umum yang diperlukan. Persyaratan yang belum dilaksanakan adalah pelatihan staf hotel, padahal hal tersebut merupakan faktor penting suksesnya pelaksanaan pemeliharaan hotel. Selain pelatihan, persyaratan umum lain yang belum dilaksanakan adalah kerja sama dengan komunitas lokal, penggunaan produk hijau, dan perlunya pengoptimalan operasional dan pemeliharaan green hotel agar menjadi efektif, efisien dan berkelanjutan. Hal-hal tersebut perlu dilaksanakan agar pemeliharaan ramah lingkungan yang dilakukan saat ini dapat memenuhi kriteria standar green hotel.

\section{KESIMPULAN DAN SARAN}

Green hotel belum banyak diterapkan di Indonesia, sehingga diharapkan Hotel Mandalawangi akan terus mengembangkan konsep green hotel agar dapat mendukung keberlanjutan, menjaga, dan memperbaiki kualitas lingkungan. Disimpulkan bahwa Hotel Mandalawangi baru menerapkan konsep green hotel sebesar 59,25\% dari total standar green hotel, sehingga masih terdapat beberapa persyaratan yang perlu diterapkan seperti mengurangi penggunaan zat kimia saat pemeliharaan kolam renang dan pelatihan yang belum dilaksanakan. Pemeliharaan yang perlu dipertahankan oleh Hotel Mandalawangi adalah efisiensi energi, air, kualitas air, dan kualitas udara. Pemeliharaan yang perlu ditingkatkan yaitu penyimpanan sementara sampah yang akan diangkut oleh petugas sampah, sedangkan yang perlu diperbaiki adalah pelatihan terhadap sumber daya manusia khususnya staf hotel dan mengurangi penggunaan zat kimia dalam operasional dan pemeliharaan hotel.

Pemeliharaan kurang baik yang dilakukan oleh Hotel Mandalawangi yaitu pemeliharaan kolam renang dengan menggunakan zat kimia dapat diminimalisir dengan penggunaan filter air yang dapat menyaring bakteri atau lumut, sehingga dapat menerapkan konsep natural swimming pool yang sangat cocok dengan konsep green hotel di Hotel Mandalawangi. Penerapan natural swimming pool juga membuktikan bahwa pemeliharaan kolam renang tidak perlu dilakukan secara terus menerus, sehingga dapat menekan biaya pemeliharaan. Untuk meningkatkan kemampuan sumber daya manusia, perlu dilaksanakan pelatihan, sosialisasi dan pemahaman kepada staf hotel dan klien mengenai green hotel setidaknya satu tahun sekali, sehingga pemeliharaan dapat terus ditingkatkan. Hotel Mandalawangi juga harus memenuhi persyaratan umum yang belum dilaksanakan, sehingga diharapkan hotel dapat diikutsertakan dalam program sertifikasi green hotel yang memberikan dampak kepada peningkatan nilai aset. 


\section{UCAPAN TERIMAKASIH}

Terima kasih kepada Hotel Mandalawangi yang bersedia untuk dijadikan objek penelitian khususnya kepada General Manager Hotel Mandalawangi yang telah membantu dan bekerja sama sejak pengajuan sebagai objek penelitian hingga artikel ini selesai disusun.

\section{DAFTAR PUSTAKA}

[BMKG] Badan Meteorologi, Klimatologi dan Geofisika. 2019. Hari meteorologi dunia, BMKG ajak masyarakat mitigasi perubahan iklim [internet]. Tersedia di: https://www.bmkg.go.id/berita/?p=hari-meteorologi-dunia-bmkg-ajakmasyarakat-mitigasi-perubahan-iklim\&lang=ID\&tag=press-release.

Chan KT, Lee RHK and Burnett J. 2001. Maintenance performance: a case study of hospitality engineering systems. Facilities 19(13):494-504.

Chan KT, Lee RHK and Burnett J. 2003. Maintenance practices and energy performance of hotel buildings, strategic planning for energy and the environment. Strategic Planning for Energy and the Environment 23(1):6-28. Chen A and Peng A. 2012. Green hotel knowledge and tourists' staying behavior. Annals of Tourism Research 39(4): 2211-2216.

Ghazi K. 2016. Hotel maintenance management practice. Journal of Hotel and Business Management 5(1):1-13.

Ivancevich JM. 2001. Human resource management. McGraw Hill. New York.

Kristiana W, Waluyo N dan Desy A. 2017. Manajemen Perawatan dan pemeliharaan bangunan gedung pada kantor Sekretariat Daerah Provinsi Kalimantan Tengah. Jurnal Teoritis dan Terapan Bidang Keteknikan 1(1):2025.

Pitt M. 2016. Hotel maintenance management in Sanya, China. Journal of Facilities Management 14(4):304-314.

Rahmafitria F. 2014. Eco-resort dan green hotel di indonesia: model sarana akomodasi yang berkelanjutan. Jurnal Manajemen Resort \& Leisure 11(2).

Sustain Ever. 2000. Green models [internet]. Tersedia di: https://sustainever .com/green-models/.

Widanaputra A. 2009. Akuntansi perhotelan pendekatan sistem informasi. Graha Ilmu. Jakarta.

Yusuf AM. 2014. Metode penelitian: kuantitatif, kualitatif \& penelitian gabungan. Prenadamedia Group. Jakarta. 